\title{
Analisis Sistem Klasifikasi Keamanan dan Akses Arsip Dinamis Universitas Sebelas Maret
}

\author{
Umi Khariroh \\ Pascasasrjana, Ilmu Perpustakaan dan Informasi - Interdiciplinary Islamic Studies UIN Sunan \\ Kalijaga Yogyakarta \\ Jl. Laksda Adisucipto, Papringan, Caturtunggal, Kec. Depok, Kabupaten Sleman, Daerah Istimewa \\ Yogyakarta 55281 \\ e-mail: Khariroh2506@gmail.com
}

\begin{abstract}
Introduction. One of the four guidelines required in the dynamic archive management process is the Security Classification System and Archive Access. Its existence is needed as a guideline for managing archives in providing access services to dynamic archives. The purpose of this research is so that the public, especially the college community, can know and implement the preparation of college regulations, especially on the Classification of Security and Access to Dynamic Archives, and implement them. The Dynamic Archive Security and Access Classification System at Sebelas Maret University is regulated based on archival legislation and college archival legislation based on rector regulations.

Research methods. This research uses qualitative methods with a stud library approach.

Data analysis. Data is analyzed by studying books, literature, records, and various reports related to research.

Results and discussion. The archiving governance of Universitas Sebelas Maret refers to government policies and regulations as well as authorized agencies such as ANRI related to archiving. The archive collection consists of textual and non-textual archives. Archives are classified into ordinary, limited, confidential and highly classified information. The classification of archives is assisted by conventional storage facilities and digital storage facilities.

Conclusions and suggestions. The classification of archival access is a category of restrictions on access to archives based on the authority to use archives related to the implementation of certain tasks and functions. Archival security is a physical protection program and archival information based on its security classification.
\end{abstract}

Keywords: Security Systems, Classifications, Dynamic Archives.

\begin{abstract}
ABSTRAK
Pendahuluan. Salah satu dari empat pedoman yang diperlukan dalam proses pengelolaan arsip dinamis adalah Sistem Klasifikasi Keamanan dan Akses Arsip. Keberadaannya diperlukan sebagai pedoman untuk mengelola arsip dalam memberikan layanan akses terhadap arsip dinamis. Tujuan dari penelitian ini adalah agar masyarakat khususnya masyarakat perguruan tinggi dapat mengetahui dan melaksanakan penyusunan peraturan perguruan tinggi khususnya tentang Klasifikasi Keamanan dan Akses Arsip dinamis, serta mengimplementasikannya. Sistem Klasifikasi Keamanan dan Akses arsip dinamis di Universitas Sebelas Maret diatur berdasarkan perundang-undangan kearsipan serta perundang undangan kearsipan perguruan tinggi berdasarkan peraturan rektor.

Metode penelitian. Penelitian ini menggunakan metode kualitatif dengan pendekatan studi pustaka.

Data analisis. data dianalisis dengan menelaah buku, literature, catatan, serta bebagai laporan yang berkaitan dengan penelitian

Hasil dan pembahasan. Tata kelola kearsipan Universitas Sebelas Maret mengacu pada kebijakan dan peraturan pemerintah serta instansi yang berwenang seperti
\end{abstract}


ANRI terkait dengan kearsipan. Koleksi arsip yag dimiliki terdiri dari arsip tekstual dan non tekstual. Arsip diklasifikasikan menjadi informasi biasa, terbatas, rahasia dan sangat rahasia. Pengklasifikasian arsip dibantu oleh sarana penyimpanan konvensional dan sarana penyimpanan digital.

Kesimpulan dan saran. Adapun klasifikasi akses arsip merupakan kategori pembatasan akses terhadap arsip berdasarkan kewenangan penggunaan arsip terkait dengan pelaksanaan tugas dan fungsi tertentu. Pengamanan arsip adalah program perlindungan fisik dan informasi arsip berdasarkan klasifikasi keamanannya.

Kata Kunci: Sistem Keamanan, Klasifikasi, Arsip Dinamis.

\section{A. PENDAhULUAN}

Keberadaan arsip bukanlah hal yang diciptakan secara khusus, tetapi arsip tercipta secara otomatis sebagai bukti pelaksanaan kegiatan administrasi atau transaksi. Arsip mempunyai nilai yang sangat penting dalam berbagai hal, selain sebagai informasi, arsip juga merupakan bahan bukti yang dapat di pertanggung jawabkan kebenarannya.

Arsip juga berperan penting dalam berbagai kegiatan administrasi, dalam kehidupan sehari-hari dan dalam berbagai bidang kegiatan. Arsip juga dapat dikatakan sebagai pusat ingatan serta sejarah dan sebagai barang bukti serta sebagai informasi baik untuk pribadi maupun masyarakat.

Di Indonesia ada perundang-undangan tentang arsip yaitu UU Nomor 43 tahun 2009. Dalam undang undang tersebut dinyatakan bahwa: kearsiapan adalah hal-hal yang berkenaan dengan arsip, arsip adalah rekaman kegiatan atau peristiwa dalam berbagai bentuk dan media sesuai dengan perkembangan teknologi informasi dan komunikasi yang dibuat dan diterima oleh lembaga negara, pemerintahan daerah, lembaga pendidikan, perusahaan, organisasi politik, organisasi kemasyarakatan, dan perseorangan dalam pelaksanaan kehidupan bermasyarakat, berbangsa, dan bernegara.

Pelaksanaan terhadap undang-undang terkait informasi maupun informasi berbasis arsip saat ini diatur dalam : (1) Peraturan Pemerintah Republik Indonesia Nomor 61 Tahun 2010 tentang Pelaksanaan Undang-undang Republik Indonesia Nomor 14 Tahun 2008 tentang Keterbukaan Informasi Publik; (2) Peraturan Pemerintah Republik Indonesia Nomor 61 Tahun 2010 tentang Pelaksanaan Undang-undang Republik Indonesia Nomor 14 Tahun 2008 tentang Keterbukaan Informasi Publik; (3) Peraturan Pemerintah Republik Indonesia Nomor 28 Tahun 2012 tentang Pelaksanaan Undang-Undang Republik Indonesia Nomor 43 Tahun 2009 tentang Kearsipan. Pelaksanaan terhadap undang-undang terkait informasi, informasi berbasis arsip, maupun pelayanan publik diatur oleh Arsip Nasional Republik Indonesia. Lembaga Negara Non Kementerian ini berdasar pada Pasal 8 huruf a Keputusan Presiden Nomor 103 Tahun 2001 tentang Kedudukan, Tugas, 
Fungsi, Kewenangan, Susunan Organisasi, dan Tata Kerja Lembaga Pemerintah Non Kementerian sebagaimana telah beberapa kali diubah, terakhir dengan Peraturan Presiden Nomor 145 Tahun 2015 tentang Perubahan Kedelapan atas Keputusan Presiden Nomor 103 Tahun 2001 tentang Kedudukan, Tugas, Fungsi, Kewenangan, Susunan Organisasi, dan Tata Kerja Lembaga Pemerintah Non Kementerian, memiliki kewenangan untuk menyusun kebijakan di bidang kearsipan. Lembaga negara ini mengatur tentang sistem klasifikasi keamanan dan akses arsip dinamis ke dalam Peraturan Kepala Arsip Nasional Republik Indonesia Nomor 17 Tahun 2011 tentang Pedoman Pembuatan Sistem Klasifikasi Keamanan dan Akses Arsip Dinamis.

Dalam rangka pengelolaan arsip dinamis dan kemudahan akses arsip bagi publik dan perlindungan terhadap keamanannya, perlu adanya klasifikasi atau pengaturan terhadap akses arsip dinamis di lingkungan Universitas Sebelas Maret untuk mencegah terjadinya penyalahgunaan arsip oleh pihak-pihak yang tidak berhak.

\section{B. KAJIAN PUSTAKA}

\section{Klasifikasi Arsip}

Arsip merupakan satu basis media yang menyimpan informasi. Robek, Mary F. and Brown, Gerald F. and Maedke, Wilmer O (1987: 3) menyatakan, bahwa informasi merupakan peralatan penting yang diperlukan sehari-hari untuk memecahgkan masalah yang terjadi. Selain itu informasi diperlukan sebagai bahan referensi kita ketika akan mengambil keputusan. Pernyataan ini sangat beralasan, karena apabila kita mengambil keputusan tanpa didasari oleh informasi yang cukup, maka bisa jadi keputusan yang diambil dapat berakibat buruk secara mikro maupun makro. Robek, dkk mengutip definisi informasi dari sebuah kamus terpilih, sebagai "knowledge communicated by others or obtained by study and investigation". Dari kutipan tersebut diketahui, bahwa informasi merupakan "sesuatu" yang mengandung "pengetahuan baru" bagi pihak yang belum pernah mengetahui sebelumnya. "Pengetahuan baru itu diperoleh melalui proses kajian dan penyelidikan. Informasi sangat diperlukan untuk menjalani kehidupan sehari-hari dalam bersosial kemasyarakatan, pekerjaan, mauipun dalam penyelenggaraan pemerintahan. Media transmisi informasi di masa lalu berupa surat konvensional, telepon, telegram, siaran radio, siaran televisi, rekaman film, rekaman dalam cassette, positif foto, dan lain-lain. Tetapi media transmisi informasi di era teknologi informasi dewasa ini sudah sangat canggih, 
sehingga media surat konvensional, telegram, sudah mulai ditinggalkan beralih ke media elektronik seperti smartphone dan sejenisnya.

\section{Arsip Dinamis}

Arsip menurut Pasal 1 butir 2 Undang-Undang Republik Indonesia Nomor 43 Tahun 2009 tentang Kearsipan adalah "rekaman kegiatan atau peristiwa dalam berbegai bentuk dan media sesuai dengan perkembangan teknologi informasi dan komunikasi yang dibuat dan diterima oleh lembaga negara, pemerintah daerah, lembaga pendidikan, perusahaan, organisasi politik, organisasi kemasyarakatan, dan perseorangan dalam pelaksanaan kehidupan bermasyarakat, berbangsa dan bernegara". Sementara itu pengertian arsip dinamis menurut Pasal 1 butir 3 dalam undang-undang yang sama disebutkan sebagai "arsip yang digunakan secara langsung dalam kegiatan pencipta arsip dan disimpan selama jangka waktu tertentu. Dari kedua pengertian tersebut dapat diketahui, bahwa arsip merupakan salah satu media informasi yang diciptakan, dan harus dikelola secara sistematis agar mudah untuk ditemu kembali ketika informasi yang dikandung di dalam arsip tersebut diperlukan.

\section{Sistem Klasifikasi Keamanan dan Akses Arsip Dinamis}

Undang-Undang Republik Indonesia Nomor 12 Tahun 2011 telah mengatur tentang hierarki peraturan perundang-undangan di Indonesia. Pedoman pembuatan sistem klasifikasi keamanan dan akses arsip diatur dalam Peraturan Kepala Arsip Nasional Republik Indonesia Nomor 17 Tahun 2011 tentang Pedoman Pembuatan Sistem Klasifikasi Keamanan dan Akses Arsip. Keberadaan peraturan tersebut menjamin bahwa publik dapat mengakses informasi berbasis arsip yang diciptakan. Kebijakan ini telah diatur dalam Undang-Undang Republik Indonesia Nomor 14 Tahun 2008 tentang Keterbukaan Informasi Publik. Namun, ketentuan tersebut dapat membahayakan keutuhan fisik arsip serta keamanan stabilitas negara apabila informasi yang direkam di dalam arsip dinamis tidak datur penggunaannya untuk publik. Atas dasar pertimbangan tersebut maka setiap organisasi harus menciptakan sistem klasifikasi keamanan dan akses arsip.

\section{METODE PENELITIAN}

Jenis penelitian ini adalah kualitatif dengan metode pengumpulan data berupa studi pustaka (library research). Penelitian kepustakaan adalah penelitian yang dilaksanakan dengan menggunakan literature (kepustakaan), baik berupa buku, catatan, maupun laporan hasil penelitian terdahulu (Hasan, 2008: 5). Penelitian kepustakaan ini juga merupakan teknik pengumpulan data dengan melakukan 
penelaahan terhadap buku, literature, catatan, serta sebagai laporan yang berkaitan dengan masalah yang ingin dipecahkan (Nazir, 1988).

\section{PEMBAHASAN}

\section{Gambaran Umum UPT Kearsipan Universitas Sebelas Maret}

Salah satu bentuk komitmen Universitas Sebelas Maret terhadap peningkatan kualitas pelayanan administrasi adalah pembenahan terhadap pengelolaan arsip. Tindak lanjut dari komitmen tersebut diawali berdirinya Pusat Arsip Universitas Sebelas Maret yang diresmikan oleh Prof. Dr. Ravik Karsidi, M.S. selaku Pembantu Rektor I, pada hari kamis 3 Maret 2005 sekaligus dalam rangka memperingati Dies Natalis XXIX UNS Tahun 2005.

Sesuai struktur organisasi, maka Pusat Arsip Universitas sebelas Maret yang telah dibentuk tersebut berada di bawah kendali Sub Bagian TU, RT, HTL Universitas Sebelas Maret. Akan tetapi seiring berjalannya waktu, maka Pusat Arsip ini dapat mengakomodir kebutuhan pengelolaan kearsipan di Universitas Sebelas Maret terlebih dengan adanya amanah Undang-undang No. 43 Tahun 2009 tentang kearsipan yang dalam salah satu pasalnya menyebutkan bahwa setiap Perguruan Tinggi Negeri wajib membentuk Lembaga Arsip Perguruan Tinggi, maka semakin mendorong Universitas untuk merealisasikannya.

Oleh karena itu dalam rangka merealisasikan amanah Undang-undang tersebut dan mengingat peningkatan fungsi dan peran penting Pusat arsip bagi UNS, maka sebagaimana tertuang dalam peraturan Menteri Pendidikan dan Kebudayaan RI Nomor 82 Tahun 2014 tentang Organisasi dan Tata Kerja Universitas Sebelas maret tertanggal 20 Agustus 2014 maka Pusat Arsip berubah status menjadi Unit Pelaksana Teknis (UPT) dengan nama UPT Kearsipan Universitas Sebelas Maret. Dan setelah hampir satu tahun, maka pada hari jum'at tanggal 3 juli 2015 ditugaskan dan dilantik kepala UPT Kearsipan yaitu Drs. Joko Sugiyatno.

UPT Kearsipan adalah unsur penunjang Universitas Sebelas Maret, dipimpin oleh seorang Kepala dan bertanggung jawab kepada Rektor dan dikoordinasikan oleh Wakil Rekstor Bidang Umum dan Keuangan yang mempunyai tugas memimpin penyelenggaraan kegiatan di bidang administrasi umum, keuangan, dan kepegawaian. UPT Kearsipan senantiasa memiliki komitmen untuk melakukan perbaikan pelayanan dan pengembangan sistem kearsipan di lingkungan Universitas Sebelas Maret, dalam rangka mendukung kelancaran kinerja UNS sebagai salah satu Perguruang Tinggi terkemuka. 


\section{Visi Misi UPT Kearsipan Universitas Sebelas Maret}

$\underline{\text { Visi }}$

Menjadi pusat rujukan dan layanan arsip perguruan tinggi dalam rangka mendukung UNS dalam mengembangkan ilmu, teknologi dan seni di tingkat Internasional.

$\underline{\text { Misi }}$

1) Menyelamatkan arsip yang bernilaiguna secara permanen/statis sebagai sumber informasi dan pengetahuan

2) Menjamin ketersediaan arsip yang autentik dan terpercaya melalui penyelenggaraan kearsipan yang sesuai dengan kaidah, prinsip dan standar kearsipan

\section{Tujuan}

1) Terciptanya pusat pelayanan/sumber informasi kearsipan sebagai media pendidikan dan pembelajaran institusi maupun umum

2) Terwujudnya pusat pengelolaan, pemeliharaan dan pelestarian arsip

3) Terwujudnya penataan kearsipan yang berhasil guna secara optimal

4) Terwujudnya pengembangan kearsipan yang berbasis teknologi informasi dalam rangka mendukung percepatan pengelolaan arsip

\section{Kebijakan Pengelolaan Arsip Universitas Sebelas Maret}

Tata kelola kearsipan Universitas Sebelas Maret mengacu pada kebijakan dan peraturan sebagai berikut (https://arsip.uns.ac.id/files/):

1) Permenpan Nomor 48 Tahun 2014 Tentang Jabatan Fungsional Arsiparis

2) Peraturan Rektor UNS Nomor 510/UN27/TU/2012 Tentang Pedoman Pola Klasifikasi dan JRA di lingkungan UNS

3) Peraturan Pedoman Penyelenggaraan Arsip 2017

4) Implementasi Peraturan Rektor UNS No. 21 Tahun 2017 Tentang Penyelenggaraan Kearsipan

5) Peraturan Pedoman Penyelenggaraan Arsip 2017

6) Pedoman Akuisisi Arsip statis

7) Pedoman Pengelolaan Arsip Dinamis Aktif

8) Pedoman Pengelolaan Arsip Dinamis Inaktif

9) Pedoman Penyusutan Arsip

10) Pedoman Pengelolaan Arsip Statis

11) Perek No. 6 Tahun 2020 Tentang Klasifikasi Arsip UNS

12) Perek No. 7 Tahun 2020 Tentang JRA UNS 
13) Perek No. 8 Tahun 2020 Tentang SKAAD UNS

14) Peraturan Rektor No. 19 Tahun 2020

15) Klasifikasi Arsip Substantif 2021

16) Klasifikasi Arsip Fasilitatif 2021

\section{Peraturan Kepala Arsip Nasional Republik Indonesia}

1) Perka No. 5 Tahun 2016

2) Perka No. 6 Tahun 2016

3) Perka No. 4 Tahun 2017

4) Perka No. 6 Tahun 2017

5) Perka No. 23 Tahun 2017

\section{Peraturan Perundang-undangan Pusat}

1) Undang-undang (UU)

UU No. 43 Tahun 2009

2) Peraturan Pemerintah (PP)

PP No. 28 Tahun 2012

\section{SKP}

1) Surat Pernyataan Melakukan Kegiatan (SPMK)

2) SKP Kosong Digunakan Untuk Penilaian SKP Arsiparis

\section{Daftar Koleksi Arsip Universitas Sebelas Maret}

Untuk daftar koleksi arsip yang terpajang di web https://arsip.uns.ac.id/home/page/3 adalah hanya arsip dinamis inaktif. Koleksi arsip tersebut terdiri dari:

1) Arsip Tekstual/Arsip Kertas

Adalah arsip-arsip yang frekuensi penggunaannya sudah menurun atau sering disebut arsip inaktif. Tetapi daftar koleksi arsip tekstual atau arsip kertas ini ada juga yang sudah dipermanenkan sehingga menjadi arsip statis. Koleksi yang tercantum di web tersebut terdiri dari 100 entri, terdiri dari 12 halaman dan 1172 items. Daftar koleksi arsip dinamis inaktif tersebut diantaranya terdiri dari:

1. Peraturan Rektor Universitas Sebelas Maret Nomor 1 Tahun 2019 tentang Pedoman Kerjasama Universitas Sebelas Maret

2. Sertifikat Akreditasi oleh BAN-PT RI No. 038/BAN-PT/AkXII/S1/I/2011 menyatakan Program Studi Sarjana Pendidikan Bahasa Inggris, Universitas Sebelas Maret (UNS), Surakarta terakreditasi B, Berlaku 5 (lima) tahun, sejak 14 Januari 2011 sampai dengan 14 Januari 2016 
3. Sertifikat Akreditasi berdasarkan Keputusan BAN-PT No. 142/SK/BAN_PT/Akred/PT/VII/2018 Universitas Sebelas Maret terakreditasi A

4. Dan koleksi lainnya yang dapat dilihat langsung di https://arsip.uns.ac.id/cari_arsip/arsip_tekstual

Daftar koleksi arsip yang dipermanenkan/ statis terdiri dari:

1. Riwayat Berdirinya UNS Tahun 1977 (dipermanenkan Tahun 1982)

2. Sejarah Perubahan Nama UNS (dipermanenkan Tahun 1987)

3. Surat Edaran Dikti tentang Penyelenggaraan Perkuliahan Pendidikan Pancasila di Perguruan Tinggi (dipermanenkan Tahun 2015)

4. Peraturan Rektor UNS No. 734A/UN27/HK/2015 tentang Pengesahan dan Pemberlakuan Falsafah Visi, Misi dan Tujuan Universitas Sebelas Maret (dipermanenkan tahun 2019)

5. Keputusan Badan Akreditasi Nasional Perguruan Tinggi Nomor 237/SK/BAN-PT/Ak-XVI/S/XI/2013 (dipermanenkan tahun 2020)

2) Arsip Non Tekstual, yang terbagi menjadi

a. Arsip Sound Recording

Yaitu arsip yang informasinya terekam dalam sinyal dan suara dengan menggunakan teknik perekaman tertentu.

b. Arsip Kearsitekturan

Adalah arsip yang berupa gambar yang merupakan bentuk visual dari seorang arsitek. Pengelolaan arsip kearsitekturan yaitu dengan membuat deskripsi atau gambaran secara terperinci tentang informasi yang terdapat dalam arsip kearsitekturan. Unsur-unsurnya meliputi pencipta, nomor kerja, nama arsitek, tanggal/bulan/tahun kearsitekturan dibuat lokasi bangunan, nama bangunan, tipe bangunan, kode klasifikasi, keterangan skala, satuan tingkat perkembangan, kondisi fisik penyimpanan, arsip kearsitekturan ditempatkan pada laci kearsitekturan dan diberi tanda untuk membedakan laci satu dengan yang lainnya berdasarkan subyek dengan urutan pengerjaannya, nama instansi, subyek, judul/tahun. Penemuan kembali arsip dilakukan dengan membuat daftar yang membuat unsur-unsurdeskripsi arsip kearsitekturan.

Daftar koleksi arsip ini hanya ada satu di web yaitu: Perencanaan Rehap Kanopi Gedung I (Ruang Sidang) dan untuk keterangan lebih jelasnya bisa dilihat di https://arsip.uns.ac.id/cari_arsip/arsip_kearsitekturan 
c. Arsip Video

Adalah arsip yang isi informasinya berupa citra bergerak (terekam dalam rangkaian fotografik dan suara pada pita magnetic yang penciptaannya menggunakan media teknologi elektronik.

\section{Sistem Klasifikasi Keamanan dan Akses Arsip Dinamis Universitas Sebelas} Maret

Sistem Klasifikasi Keamanan dan Akses Arsip Dinamis yang selanjutnya disingkat SKKAAD adalah aturan pembatasan hak akses terhadap fisik dan informasinya sebagai dasar untuk menentukan keterbukaan dan kerahasiaan arsip dalam rangka melindungi hak dan kewajiban pencipta arsip dan pengguna dalam pelayanan arsip.

\section{a. Maksud dan Tujuan penyusunan}

Maksud penyusunan SKKAAD adalah sebagai berikut:

a. Mendorong unit pengolah agar memberkaskan arsip dinamis unit kerjanya secara tertib yang disertai dengan daftar arsip aktifnya;

b. Memberikan petunjuk kepada unit pengolah agar dapat mengamankan dan mematuhi kewenangan akses terhadap klasifikasi informasi arsip yang telah ditetapkan;

c. Melindungi fisik dan informasi arsip dari kerusakan dan kehilangan sehingga ketersediaan, keterbacaan, keutuhan, otentisitas dan realibilitas arsip dapat tetap terjaga;

d. Melindungi arsip dari pengaksesan yang tidak sesuai aturan sehingga dapat dicegah terjadinya penyalahgunaan arsip oleh pihak yang tidak berhak untuk tujuan dan kepentingan yang tidak sah.

Adapun tujuan penyusunan SKKAAD adalah sebagai berikut:

a. Menjadi acuan pelaksanaan dalam pengelolaan arsip dinamis di Universitas;

b. Menyediakan layanan informasi arsip dinamis kepada publik dengan prinsip cepat, tepat, murah, dan aman;

c. Tersedianya informasi universitas yang dikategorikan terbuka dan dapat diakses seluas-luasnya bagi publik sesuai dengan lampiran klasifikasi keamanan dan akses arsip dinamis;

d. Terjaminnya keamanan arsip bagi informasi yang dikecualikan; dan 
e. Terciptanya kenyamanan bekerja bagi seluruh pegawai di Universitas Sebelas Maret

\section{b. Ruang lingkup}

Adapun ruang lingkup dalam SKKAAD mencakup:

a. Klasifikasi keamanan arsip, memuat informasi terbatas, rahasia dan sangat rahasia; biasa/ umum/ terbuka,

b. Pengamanan arsip, memuat pengamanan ruang pengelola arsip, serta daftar informasi terbatas, rahasia;

c. Klasifikasi dan pengaturan akses arsip, memuat pengguna internal dan pengguna eksternal.

\section{c. Ketentuan dalam SKKAAD}

Sistem klasifikasi keamanan dan akses arsip dinamis di Universitas Sebelas Maret diatur dengan ketentuan sebagai berikut:

a. Arsip yang tercipta di Universitas dapat diklasifikasikan menjadi informasi biasa, terbatas, rahasia dan sangat rahasia;

b. Keempat tingkat klasifikasi sebagaimana dimaksud pada huruf a, berbeda dalam teknis pengamanannya, semakin tinggi tingkat klasifikasi informasinya semakin tinggi pula tingkat pengamanannya;

c. Keempat tingkat klasifikasi sebagaimana dimaksud pada huruf a, berbeda dalam pengaturan aksesnya, semakin tinggi tingkat klasifikasi informasinya semakin ketat pura dalam pengaturan aksesnya;

d. Setiap pegawai Universitas hanya dapat mengakses arsip yang berada pada tanggung jawab tugas dan kewenangannya; dan

e. Publik dapat mengakses informasi Universitas yang dikategorikan terbuka sesuai dengan prosedur yang telah ditentukan.

Sarana sistem klasifikasi keamanan dan akses arsip dinamis di Universitas Sebelas Maret menggunakan sarana perangkat keras (hardware) dan perangkat lunak (Software). Perangkat keras (hardware) meliputi:

a. Sarana penyimpanan arsip konvensional berupa filing cabinet/rak arsip untuk menyimpan arsip biasa/terbuka dan terbatas, dan brankas atau lemari besi untuk arsip rahasia dan sangat rahasia; 
b. Sarana penyimpanan arsip media baru berupa lemari arsip sesuai dengan tingkat klasifikasi informasi

c. Prasarana berupa ruang penyimpanan yang representatif sesgai dengan tingkat klasifikasi informasi.

Adapun perangkat lunak (software) meliput daftar arsip aktif, inaktif, terjaga dan vital, Aplikasi pengelolaan arsip aktif dan inaktif. 
Tabel 1 : Contoh Kolom Sistem Klasifikasi Keamanan dan Akses Arsip Dinamis Substantif di Universitas Sebelas Maret

\begin{tabular}{|c|c|c|c|c|c|c|c|c|c|c|c|c|}
\hline \multirow[t]{2}{*}{$\mathrm{NO}$} & \multirow[t]{2}{*}{$\begin{array}{l}\text { KLASIFIKAS } \\
\text { I }\end{array}$} & \multirow[t]{2}{*}{ JENIS ARSIP } & \multirow[t]{2}{*}{$\begin{array}{l}\text { KLASIFIKASI } \\
\text { KEAMANAN }\end{array}$} & \multicolumn{5}{|c|}{$\begin{array}{c}\text { PENGGUNA } \\
\text { YANG BERHAK } \\
\text { AKSES* }\end{array}$} & \multirow[t]{2}{*}{ HAK AKSES } & \multirow[t]{2}{*}{$\begin{array}{c}\text { DASAR } \\
\text { PERTIMBANGAN }\end{array}$} & \multirow{2}{*}{$\begin{array}{c}\text { DASAR } \\
\text { HUKUM } \\
\text { (TERBATAS } \\
\text { DAN RAHASIAJ }\end{array}$} & \multirow[t]{2}{*}{$\begin{array}{c}\text { UNIT } \\
\text { PENGOLAH }\end{array}$} \\
\hline & & & & 1 & 2 & 3 & 4 & 5 & & & & \\
\hline 1 & 2 & 3 & 4 & 5 & 6 & 7 & 8 & 9 & 10 & 11 & 12 & 13 \\
\hline I & PR & PERENCANAAN & & & & & & & & & & \\
\hline \multirow[t]{4}{*}{1} & $\begin{array}{c}\text { PR.00 } \\
\text { PR.00. } 00\end{array}$ & $\begin{array}{l}\text { Pokok-pokok Kebijakan dan Strategi } \\
\text { Pembangunan } \\
\text { a Rencana Pembangunan Jangka } \\
\text { Panjang/ Master Plan (RPJP) Bidang } \\
\text { Pendidikan, Rencana Induk } \\
\text { Pengembangan Kampus (RIPK) }\end{array}$ & Biasa/Terbuka & & & & & & $\begin{array}{l}\text { Kepala Bagian } \\
\text { Perencanaan }\end{array}$ & $\begin{array}{l}\text { Tidak memiliki } \\
\text { dampak yang } \\
\text { mengganggu } \\
\text { kinerja Universitas } \\
\text { Sebelas Maret }\end{array}$ & & $\begin{array}{c}\text { Bagian } \\
\text { Perencanaan }\end{array}$ \\
\hline & PR.00.01 & $\begin{array}{ll}\text { b } & \text { Rencana Pembangunan Jangka } \\
& \text { Menengah/ RPJM Bidang Pendidikan } \\
& \text { Rencana Strategis }\end{array}$ & Biasa/Terbuka & & & & & & $\begin{array}{c}\text { Kepala Bagian } \\
\text { Perencanaan }\end{array}$ & $\begin{array}{l}\text { Tidak memiliki } \\
\text { dampak yang } \\
\text { mengganggu } \\
\text { kinerja Universitas } \\
\text { Sebelas Maret }\end{array}$ & & $\begin{array}{c}\text { Bagian } \\
\text { Perencanaan }\end{array}$ \\
\hline & PR.00. 02 & c Rencana Operasional & Biasa/Terbuka & & & & & & $\begin{array}{c}\text { Kepala Bagian } \\
\text { Perencanaan }\end{array}$ & $\begin{array}{l}\text { Tidak memiliki } \\
\text { dampak yang } \\
\text { mengganggu } \\
\text { kinerja Universitas } \\
\text { Sebelas Maret }\end{array}$ & & $\begin{array}{c}\text { Bagian } \\
\text { Perencanaan }\end{array}$ \\
\hline & PR.00.03 & $\begin{array}{l}\mathrm{d} \text { Program Kerja Tahunan/ RKAKL } \\
\text { (Rencana Kerja Anggaran Kementerian } \\
\text { / Lembaga) } \\
\text { 1) Usulan dari unit kerja dan data } \\
\text { pendukungnya }\end{array}$ & Biasa/Terbuka & & & & & & $\begin{array}{l}\text { Kepala Bagian } \\
\text { Perencanaan }\end{array}$ & $\begin{array}{l}\text { Tidak memiliki } \\
\text { dampak yang } \\
\text { mengganggu } \\
\text { kinerja Universitas } \\
\text { Sebelas Maret }\end{array}$ & & $\begin{array}{c}\text { Bagian } \\
\text { Perencanaan }\end{array}$ \\
\hline
\end{tabular}




\begin{tabular}{|c|c|c|c|c|c|c|c|c|c|c|c|c|}
\hline \multirow[t]{2}{*}{$\mathrm{NO}$} & \multirow[t]{2}{*}{ KLASIFIKASI } & \multirow[t]{2}{*}{ JENIS ARSIP } & \multirow[t]{2}{*}{$\begin{array}{l}\text { KLAS IFIKAS I } \\
\text { KEAMANAN }\end{array}$} & \multicolumn{5}{|c|}{$\begin{array}{l}\text { PENGGUNA } \\
\text { YANGBERHAK } \\
\text { AKSES* } \\
\end{array}$} & \multirow[t]{2}{*}{ HAKAKSES } & \multirow[t]{2}{*}{$\begin{array}{c}\text { DASAR } \\
\text { PERTIMBANGAN }\end{array}$} & \multirow{2}{*}{$\begin{array}{c}\text { DASAR } \\
\text { HUKUM } \\
\text { (TEHBATAS } \\
\text { DAN RAHASIA }\}\end{array}$} & \multirow[t]{2}{*}{$\begin{array}{c}\text { UNIT } \\
\text { PENGOLAH }\end{array}$} \\
\hline & & & & 1 & 2 & 3 & 4 & 5 & & & & \\
\hline 1 & 2 & 3 & 4 & $\mathrm{~S}$ & 6 & 7 & 8 & 9 & 10 & 11 & 12 & 13 \\
\hline \multirow[t]{4}{*}{9} & $\begin{array}{c}\text { TI.08 } \\
\text { TI.08. } 00\end{array}$ & $\begin{array}{l}\text { Manajemen Risiko TI } \\
\text { a Identitas risiko TI }\end{array}$ & Terbatas & & & & & & $\begin{array}{c}\text { Kepala UPT } \\
\text { TIK }\end{array}$ & $\begin{array}{l}\text { Memiliki dampak } \\
\text { yang dapat } \\
\text { mengungkap data } \\
\text { rahasia badan } \\
\text { publik }\end{array}$ & $\begin{array}{l}\text { Pasal } 17 \text { huruf } \\
\text { i Undang- } \\
\text { Undang Nomor } \\
14 \text { Tahun } 2008\end{array}$ & UPT TIK \\
\hline & TI.08. 01 & b Penilaian Risiko TI & Terbatas & & & & & & $\begin{array}{c}\text { Kepala UPT } \\
\text { TIK }\end{array}$ & $\begin{array}{l}\text { Memiliki dampak } \\
\text { yang dapat } \\
\text { mengungkap data } \\
\text { rahasia badan } \\
\text { publik }\end{array}$ & $\begin{array}{l}\text { Pasal } 17 \text { huruf } \\
\text { i Undang- } \\
\text { Undang Nomor } \\
14 \text { Tahun } 2008\end{array}$ & UPT TIK \\
\hline & TI.08. 02 & c $\quad$ Pengendalian Risiko TI & Terbatas & & & & & & $\begin{array}{l}\text { Kepala UPT } \\
\text { TIK }\end{array}$ & $\begin{array}{l}\text { Memiliki dampak } \\
\text { yang dapat } \\
\text { mengungkap data } \\
\text { rahasia badan } \\
\text { publik }\end{array}$ & $\begin{array}{l}\text { Pasal } 17 \text { huruf } \\
\text { i Undang- } \\
\text { Undang Nomor } \\
\text { 14 Tahun } 2008\end{array}$ & UPT TIK \\
\hline & TI.08.03 & $\begin{array}{ll}\text { d } & \text { Pemantauan dan Evaluasi Penanganan } \\
& \text { Risiko TI }\end{array}$ & Terbatas & & & & & & $\begin{array}{l}\text { Kepala UPT } \\
\text { TIK }\end{array}$ & $\begin{array}{l}\text { Memiliki dampak } \\
\text { yang dapat } \\
\text { merigungkap data } \\
\text { rahasia badan } \\
\text { publik }\end{array}$ & $\begin{array}{l}\text { Pasal } 17 \text { huruf } \\
\text { i Undang- } \\
\text { Undang Nomor } \\
14 \text { Tahun } 2008\end{array}$ & UPT TIK \\
\hline 10 & TI.09 & Pemetaan TI & Biasa/Terbuka & & & & & & $\begin{array}{l}\text { Kepala UPT } \\
\text { TIK }\end{array}$ & $\begin{array}{c}\text { Tidak memiliki } \\
\text { dampak yang } \\
\text { mengganggu } \\
\text { kinerja Universitas } \\
\text { Sebelas Maret }\end{array}$ & & UPT TIK \\
\hline $\mathrm{XI}$ & PA & PENGAWASAN & & & & & & & & & & \\
\hline
\end{tabular}




\begin{tabular}{|c|c|c|c|c|c|c|c|}
\hline 1 & $\begin{array}{c}\text { PA. 00 } \\
\text { PA. } 00.01\end{array}$ & $\begin{array}{l}\text { Rencana Pengawasan } \\
\text { a Rencana Strategis Pengawasan }\end{array}$ & Terbatas & Ketua SPI & $\begin{array}{l}\text { Memiliki dampak } \\
\text { yang dapat } \\
\text { mengungkap data } \\
\text { rahasia badan } \\
\text { publik }\end{array}$ & $\begin{array}{l}\text { Pasal } 17 \text { huruf } \\
1 \text { Undang- } \\
\text { Undang Nomor } \\
14 \text { Tahun } 2008 \\
\text { Pasal } 44 \text { ayat } 1 \\
\text { huruf i } \\
\text { Undang- }\end{array}$ & SPI \\
\hline
\end{tabular}




\begin{tabular}{|c|c|c|c|c|c|c|c|c|c|c|c|c|}
\hline \multirow[t]{2}{*}{ NO } & \multirow[t]{2}{*}{ KLASIFIKASI } & \multirow[t]{2}{*}{ JENIS ARSIP } & \multirow[t]{2}{*}{$\begin{array}{l}\text { KLASIFIHAS I } \\
\text { KEAMANAN }\end{array}$} & \multicolumn{5}{|c|}{$\begin{array}{c}\text { PENGGUNA } \\
\text { YANGBERHAK } \\
\text { AKSES* } \\
\end{array}$} & \multirow[t]{2}{*}{ HAK AKSES } & \multirow[t]{2}{*}{$\begin{array}{c}\text { DASAR } \\
\text { PERTIMBANGAN }\end{array}$} & \multirow{2}{*}{$\begin{array}{c}\text { DASAR } \\
\text { HUKUilf } \\
\text { (TERBATAS } \\
\text { DAN RAHASIA] }\end{array}$} & \multirow[t]{2}{*}{$\begin{array}{c}\text { UNIT } \\
\text { PENGOLAH }\end{array}$} \\
\hline & & & & 1 & 2 & 3 & 4 & 5 & & & & \\
\hline 1 & 2 & 3 & 4 & 5 & 6 & 7 & 8 & 9 & 10 & 11 & 12 & 13 \\
\hline 9 & BU.08 & Laporan Unit Usaha & Terbatas & & & & & & Kepala BPU & $\begin{array}{l}\text { Memiliki dampak } \\
\text { yang dapat } \\
\text { mengungkap data } \\
\text { rahasia badan } \\
\text { publik }\end{array}$ & & $\overline{\mathrm{BPU}}$ \\
\hline 10 & BU. 10 & $\begin{array}{l}\text { Layanan Toga } \\
\text { 1) Pengambilan toga } \\
\text { 2) Pengembalian toga }\end{array}$ & Biasa/Terbuka & & $\mathrm{x}$ & & & & Kepala BPU & $\begin{array}{l}\text { Tidak memiliki } \\
\text { dampak yang } \\
\text { mengganggu } \\
\text { kinerja Universitas } \\
\text { Sebelas Maret }\end{array}$ & & $\mathrm{BPU}$ \\
\hline
\end{tabular}

*) Keterangan Pengguna Hak Akses

1 : Penentu Kebijakan

2 : Pelaksana Kebijakan

3 : Pengawas Internal/Eksternal

4 : Publik

5 : Penegak Hukum 


\section{E. KESIMPULAN}

Klasifikasi keamanan arsip merupakan kategori kerahasiaan informasi arsip berdasarkan pada tingkat keseriusan dampak yarrg ditimbulkannya terhadap kepentingan dan keamanan negara, masyarakat dan perorangan. Adapun klasifikasi akses arsip merupakan kategori pembatasan akses terhadap arsip berdasarkan kewenangan penggunaan arsip terkait dengan pelaksanaan tugas dan fungsi tertentu. Pengamanan arsip adalah program perlindungan fisik dan informasi arsip berdasarkan klasifikasi keamanannya. Dalam pelaksanaan Sistem klasifikasi keamanan dan akses arsip dinamis di Universitas Sebelas Maret berdasarkan Peraturan Rektor Universitas Sebelas Maret Nomor 8 Tahun 2020 Tentang Sistem Klasifikasi Keamanan Dan Akses Arsip Dinamis Universitas Sebelas Maret.

\section{DAFTAR PUSTAKA}

IqbaI Hasan, 2008. Analisis Data Penelitian Dengan Statistik, Jakarta: Bumi aksara.

Moh. Nazir, 1988. Metodologi Penelitian, Jakarta: Ghalia Indonesia.

Peraturan Kepala Arsip Nasional Republik Indonesia Nomor 17 Tahun 2011 tentang Pedoman Pembuatan Sistem Klasifikasi Keamanan dan Akses Arsip Dinamis

Peraturan Menteri Riset, Teknologi, dan Pendidikan Tinggi Nomor 78 Tahun 2017 tentang Penyelenggaraan Kearsipan di Lingkungan Kementerian Riset, Teknologi, dan Pendidikan Tinggi Peraturan Menteri Riset, Teknologi, dan Pendidikan Tinggi Republik Indonesia Nomor 23 Tahun 2018 tentang Klasifikasi Arsip, Jadwal Retensi Arsip, dan Sistem Klasifikasi Keamanan dan Akses Arsip Dinamis di Lingkungan Kementerian Riset, Teknologi, dan Pendidikan Tinggi

Peraturan Pemerintah Nomor 61 Tahun 2010 tentang Pelaksanaan Undangundang Nomor 14 Tahun 2008 tentang Keterbukaan Informasi Publik

Peraturan Pemerintah Republik Indonesia Nomor 28 Tahun 2012 tentang Pelaksanaan Undang-Undang Republik Indonesia Nomor 43 Tahun 2009 tentang Kearsipan

Peraturan Rektor Universitas Sebelas Maret Nomor : 8 Tahun 2020 tentang Sistem Klasifikasi Keamanan dan Akses Arsip Dinamis 
Robek, Mary F. and Brown, Gerald F. and Maedke, Wilmer O., 1987. Information and Records Management (Third Edition). Mission Hills, .California: Glencoe Publishing Company.

Undang-undang Nomor 43 Tahun 2009 Tentang Kearsipan

Universitas Sebelas Maret, Kebijakan Pengelolaan Arsip Universitas Sebelas Maret, https://arsip.uns.ac.id/files 